\title{
Diarroheal Diseases; Still a Public Health Problem?
}

\author{
Aditya Shakya \\ BPH $24^{\text {th }}$ Batch
}

Diarrhoea is caused by a variety of micro-organisms including viruses, bacteria and protozoans. Diarrhoea causes a person to lose both water and electrolytes, which leads to dehydration and, in some cases, to death.

About 4 billion cases of diarrhoea per year cause 1.8 million deaths, over 90 per cent of them (1.6 million) among children under five. Repeated episodes of diarrhoeal disease makes children more vulnerable to other diseases and malnutrition. Diarrhoea is the most important public health problem directly related to water and sanitation. The simple act of washing hands with soap and water can cut diarrhoeal disease by one-third. Next to providing adequate sanitation facilities, it is the key to preventing waterborne diseases. In the world, around 4 billion diarrheal cases per year is prevalent among under 5 children. About $78 \%$ morality due to diarrheal disease is alone in south-east Asian and African countries. Many diarrheal disease outbreaks are occurring in different countries of which recent is in Nepal and Haiti.

The sole quantitative environmental target in the Millennium Development Goals is the call to "reduce by half the proportion of people without sustainable access to safe drinking water." Providing water has a number of benefits, but a key rationale for this goal is the impact of poor quality water on human health, particularly on diarrheal disease, which kills 2 million children in poor countries each year (WHO 2002; Kosek, Bern, and Guerant 2003).

Water destined for human contact that is exposed to the environment is a potential source of diarrheal disease. In developing countries, in particular, surface water is often contaminated with pathogens (including bacteria, viruses, and parasites) due to contact with human and livestock waste. Drinking, handling, cooking, and bathing in such water exposes people, especially young children, to a wide range of health risks, including diarrheal diseases. Moreover, the lack of adequate water of any kind reduces the opportunity to wash people, food, dishes, and clothes and thus contributes to the spread of disease. The health cost of diseases transmitted is tremendous and falls disproportionately on young children and in their families. Diarrheal illnesses accounted for at least 8 percent of total lost disabilityadjusted life years in developing countries in 1990 (Smith, Corvalan, and Kjellstrom 1999) and for some 20 percent of deaths among children under age five (Kosek, Bern, and Guerant 2003). Acute diarrhea can result in severe dehydration, and persistent may predispose children to malnutrition, making them more susceptible to other infectious diseases. Rotavirus is a leading cause of severe diarrheal disease and dehydration in infants. It most frequently attacks children 6-24 months and causes 20 percent of all diarrheal deaths among children under age five .In developing countries rotavirus gastroenteritis is responsible for approximately half a million deaths per year among children under age five (Parashar and others 2003).

In Nepal, around 2 million diarrheal cases per year is prevalent. According to NDHS 2006, 1 in every 25 child death is due to diarrhea. Diarrhea prevalence among under 5 children is $19 \%$ according to 2001 DHS, $12 \%$ according to 2006 DHS and 14\% according to 2009 mid DHS survey. Diarrheal disease incidence is increasing year by year among under 5 children. It is the $2^{\text {nd }}$ most common cause of death in under 5 children. It not only causes death but also disability.

\begin{tabular}{l|l|l|l}
\hline Control of diarroheal disease (CDD) & $063 / 64$ & $064 / 65$ & $065 / 66$ \\
\hline $\begin{array}{l}\text { Incidence of diarmea/1000 } \\
<5 \text { dhildren new cases }\end{array}$ & 185 & 378 & 488 \\
\hline $\begin{array}{l}\text { o of severe dehydration among total } \\
\text { new cases }\end{array}$ & $1.0 \%$ & $0.9 \%$ & $0.58 \%$ \\
\hline Case fatality rate/1000 5 dildren & 0.17 & 0.15 & 0.08 \\
\hline
\end{tabular}

In Mid-western development region and far-western development region, diarrheal cases are increasing year by year. In the year 2066, Jajarkot, Rukum were high epidemic area and many deaths occurred. Similarly, in the year 2067, Banke, Nepalganj were high epidemic area. In the year 2068, some deaths have been reported in Palpa,Dailekh and Rukum districts. Usually highest cases are reported in between the months of Shrawan and Bhadra. World is in the stage of artificial organ and organ transplantation but even now diarrhea is cause of death in Nepal. We are lagging by centuries than developed world. Time has come to once we all think it seriously and critically.

In case of Haiti's outbreak, Nepalese soldier were blamed for the cause of outbreak but Nepal government remained still on the issue. No one should be blamed without evidence based research and Nepal government should appeal to find out the actual causation of Haiti's outbreak.

Counting the deaths toll and providing medical relief in epidemic and outbreak situation is not the solution at all. It has been several decades that the effective treatment and management of diarrhoeal disease had been explored but still thousands of people are dying of Diarrhoea in Nepal alone. This clearly reflects that we are really lacking in prevention; primordial and primary prevention and our all effort has gone to treatment and disaster relief and management. Time has come to revisit our plans and policies. Proactive effective prevention activities should be given a priority. Knowledge and skills on simple 
preventive measures like hand washing and water treatment has to be delivered through behavioral change communication activities. Diarrhoeal disease is a public health priority. Its prevention requires multi-sectoral approach from different level. A combined effort of these sectors gives a strong push to Diarrhoeal disease prevention and control.

So Think globally, act locally and start immediately in diarrhoeal prevention and control! Let's not the other Jajorkot and Haiti epidemic happen again.

\section{References}

1. Alix Peterson Zwane \& Michael Kremer.WHAT
WORKS IN FIGHTING DIARRHEAL DISEASES IN DEVELOPING COUNTRIES? March 2007 NATIONAL BUREAU OF ECONOMIC RESEARCH 1050 Massachusetts Avenue. Available from http:// www.nber.org/papers/w12987

2. Ministry of Health and population,Annual report 206566, Departement of health service Teku Kathmandu Nepal

3. Diarrheal Diseases in Less Developed Countries.CDC Atlanta 2011 (cited sept 18). available form http:// www.cdc.gov/healthywater/hygiene/ldc/ diarrheal_diseases.html 